\title{
La confrontación partidista española a propósito de América Latina
}

\section{The Partisan Abuse of Latin America in Spain}

\author{
Joan del Alcàzar Garrido ${ }^{1}$ \\ ORCID: https://orcid.org0000-0001-6584-689X \\ Indira Betancourt López ${ }^{2}$ \\ ORCID: https://orcid.org/0000-0002-0640-5338 \\ Universidad de Valencia (España)
}

Recibido: 18-02-2020

Aceptado: 07-10-2020

\section{Resumen}

América Latina ha sido desde siempre objeto de controversia en España, aunque últimamente con mayor intensidad se ha convertido en materia de utilización partidista, especialmente por parte de un bloque conservador que se esfuerza en convertir hechos y procesos latinoamericanos en elementos de confrontación política interna española. También las izquierdas hispanas tienen presente a América latina en su acción política, y padecen una elevada desinformación, mientras mantienen clichés de otra época. El artículo atiende a tres casos en la confrontación derecha/izquierda de los últimos tiempos: Venezuela, ariete conservador contra el Gobierno de Pedro Sánchez; México, como excitante del nacionalismo españolista tras la exigencia de López Obrador; y, finalmente, Bolivia tras la forzada salida del poder de Evo Morales. Bolivia.

Palabras-clave: América Latina, España, partidismo, Venezuela, México,

\footnotetext{
${ }^{1}$ (jalcazar@uv.es). Catedrático de Historia Contemporánea en la Universitat de València.Su último libro es ¿Qué fue de las grandes alamedas? Chile, 1970-2020. De la victoria de Allende a la actual crisis de Estado. Valencia, Tirant lo Blanch 2020. Ha sido director del Centre Internacional de Gandia de la UV, vicerrector de profesorado de la UV y es miembro del grupo de investigación LOCSUS-UV.

2 (inbelo@uv.es). Licenciada en Historia por la Universidad de Oriente (Cuba). Máster en Estudios Cubanos y del Caribe, Máster en Cooperación al Desarrollo de la UV. Su último libro es El desarrollo local en Cuba. Obstáculos para el diseño y aplicación de políticas para un desarrollo sostenible, PUV, 2018. Ha sido Presidenta del Movimiento Científico Juvenil de Santiago de Cuba; y es miembro del grupo de investigación LOCSUS-UV.
} 


\begin{abstract}
Latin America has always been a subject of controversy in Spain, although lately more intensely it has become a matter of partisan use, especially by a conservative bloc that strives to turn Latin American facts and processes into elements of Spanish domestic political confrontation. The Hispanic lefts also keep Latin America in mind in its political action, and they suffer from high misinformation, while holding clichés from another era. The article deals with three cases in the right/left confrontation of recent times: Venezuela, a conservative weapon against Pedro Sánchez's government; Mexico, as an enhancer of Spanish nationalism due to the demand of López Obrador; and, finally, Bolivia after Evo Morales’ forced removal from presidency.
\end{abstract}

Key-words: Latin America, Spain, Partisanship, Venezuela, Mexico, Bolivia.

\title{
Introducción
}

Desde siempre ha habido diferencias entre la izquierda y la derecha españolas a la hora de abordar cualquier asunto relativo a América Latina. Incluso en la forma de denominar a aquella región. Mientras que la derecha, el conservadurismo español, gustaba y gusta de hablar de Hispanoamérica, la izquierda, el progresismo hispano, gustaba más de hablar de Iberoamérica ya desde finales del siglo XIX, aunque desde hace algunas décadas ha asumido que debe denominar a la región Latinoamérica o América Latina.

El bloque conservador se ha mantenido en unas posiciones que conectaban al Imperio en el que no se ponía el sol, la llamada evangelización y la lengua española como elementos fundantes de aquellas tierras con sus gentes ${ }^{3}$. Siempre ha hablado de descubrimiento, de la gesta de los conquistadores, hasta el punto de que el joven líder del Partido Popular, Pablo Casado, ha rechazado la idea de que España colonizara América y ha ensalzado su "grandeza" afirmando que "nosotros no colonizábamos, lo que hacíamos era tener una España más grande" . En ese marco mental hay que interpretar el llamativo éxito de ventas

\footnotetext{
3 "Fuimos, con Portugal, protagonistas inequívocos de las lógicas imperiales de la primera oleada colonial y, sin embargo, ese pasado ha quedado edulcorado en el inconsciente colectivo. De nosotros no se puede decir que tuviéramos colonias en aquellas Nuevas Indias. Si acaso, tuvimos provincias donde, según la memoria colectiva y emocionalmente ensimismada, educamos y evangelizamos a unos pobladores que más que hombres, y pese a nuestro altruista Fray Bartolomé de las Casas, eran bípedos sin plumas. Por eso, no cabe pedir disculpas a quienes experimentaron depredación y muerte. Fueron beneficiarios, no damnificados" Vid. Jesús Izquierdo Martín, "Imperio sin colonialismo: espejo del narciso español", en Conversación sobre la historia, https://conversacionsobrehistoria. info/2020/07/21/imperio-sin-colonialismo-espejo-del-narciso-espanol/

${ }^{4}$ Pablo Casado tiene sus propias ideas sobre la historia de España en América: "Fuimos la primera
} 
de algún libro que defiende de forma tan agresiva como poco fundamentada ese "engrandecimiento", supuestamente atacado por una leyenda negra promovida por "los ancestrales enemigos de España".

El bloque progresista se ha mostrado siempre, no es ninguna sorpresa, mucho más plural, menos homogéneo que el conservador. No solo asumió el concepto de Iberoamérica con el afán de incluir a Brasil y la lengua portuguesa, sino que aceptó sin problemas el concepto de América Latina que es el que, influencia francesa mediante, adoptaron la mayor parte de los naturales de las tierras al sur del Río Grande. A partir de esta posición común, la izquierda, la reformista y la que es más aguerrida, han hecho gala de un conocimiento bastante superficial de la historia latinoamericana, con una enorme carga moral y una idealización muy acrítica de lo sucedido en el subcontinente en su época más reciente, concretamente desde la revolución cubana hasta el bolivarianismo.

La izquierda española ha quedado anclada en clichés de los años sesenta y setenta, y la constatación reiterada e indiscutible de que el subcontinente americano es la región más injusta y desigual del planeta, unido a la violencia extrema que ha padecido -incluyendo Terrorismo de Estado y violaciones apocalípticas de los derechos humanos- ha conformado una imagen dual y bastante maniquea de la América Latina del siglo XXI, muy parecida a la vigente durante las décadas de la Guerra Fría.

La región que va desde la frontera sur de los Estados Unidos hasta la Patagonia constituye, a ojos de una buena parte de las izquierdas españolas, una tierra de insurgencia, una tierra en la que todavía son posibles las utopías emancipadoras, los sueños de una transformación radical que acabe de raíz con la injusticia y la desigualdad hirientes de aquellas tierras. La escritora chilena Marcela Serrano, en declaraciones motivadas por la edición de una de sus novelas, ambientada en el Chiapas de los tiempos del Subcomandante Marcos, afirmaba: "En alguna parte de su subconsciente, los extranjeros [y los españoles de izquierdas entre los primeros] siempre buscan respuestas en América Latina. Creo que tiene que ver con la orfandad revolucionaria, con la posibilidad de creer que las utopías aún son posibles".

Podría decirse que las derechas y las izquierdas españolas no hilan con mucha finura en sus posicionamientos ante la realidad latinoamericana actual y, casi de forma automática, siguen enzarzándose en una lógica binaria de apoyo a quienes en aquella región consideran sus afines y de rechazo vehemente a quienes consideran sus antagonistas ideológicos.

nación que venía de un imperio que llamábamos españoles a aquellos que formaron parte de las colonias [...] Y después de las independencias hemos seguido teniendo una relación excelente con las repúblicas latinoamericanas" [sic]. Vid. eldiario.es, 17.11.2018.https://www.eldiario.es/politica/ Casado-Historia-colonizabamos-haciamos-Espana_0 836766521.html

${ }^{5}$ Elvira Roca Barea, Imperiofobia y leyenda negra: Roma, Rusia, Estados Unidos y el Imperio español, Madrid, Siruela, 2016.

${ }^{6}$ Cartelera Turia, número 1975, diciembre de 2001.

Araucaria. Revista Iberoamericana de Filosofia, Politica, Humanidades y Relaciones Internacionales, año $23, \mathrm{n}^{\circ} 46$. Primer cuatrimestre de 2021. Pp. 173-194. ISSN 1575-6823 e-ISSN 2340-2199 https://dx.doi.org/10.12795/araucaria.2021.i46.09 


\section{Conservadores y progresistas padecen falta de información sobre la América Latina actual}

El bloque conservador se ha mostrado muy comprensivo ante la expulsión del poder de Evo Morales en Bolivia, mientras que ha mantenido una hostilidad indisimulada contra las opciones de gobierno vinculadas al populismo de izquierdas, como por ejemplo el que representa el bolivarianismo o, con mayor solera, el marco ideológico que puede conectarse con el castrismo cubano, incluso ahora que ambos viven horas muy bajas.

Las izquierdas sintonizan ideológicamente con quienes se rebelan contra la dura injusticia social y, por defecto, simpatizan y se identifican con aquellos que se revuelven contra el clasismo y el racismo de las derechas americanas en particular y del imperialismo en general. En demasiadas ocasiones, no obstante, el juego resulta demasiado simple, y más moral que político. Con frecuencia ese posicionamiento se hace de forma completamente acrítica, porque la ética impide la analítica. Pablo Stefanoni lo ha explicado: "Venezuela acabó por ser un peso político para las izquierdas, cada vez más y mejor aprovechado por las derechas para construir fantasmas de "venezuelización". Frente a este escenario, en el que el proceso venezolano resulta cada vez más alejado de visiones emancipatorias, gran parte de las izquierdas carecieron de herramientas teórico-políticas para dar cuenta de lo que estaba ocurriendo"7.

Hay más ejemplos. Citemos el nicaragüense y el cubano. Defender el régimen de Daniel Ortega, el libertador sandinista reconvertido hoy en tirano, como negar que el sistema cubano no da más de sí y la huida es la alternativa para miles de isleños, son expresiones de esa obcecación en negar la realidad, en refugiarse en unos apriorismos con fuerte carga ideológica.

Un caso interesante es el de Alberto Garzón, joven y talentoso ministro de consumo en el actual gobierno de coalición entre el PSOE y Unidas Podemos, comunista militante. Garzón borró, tras su nombramiento, un tweet de 2012 en el que decía, literalmente: "El único país cuyo modelo de consumo es sostenible y tiene un desarrollo humano alto es Cuba"s.

Podemos proponerlo como una muestra de aquella pauta anunciada anteriormente: demasiada ideología y un déficit notable de información concreta la del economista Garzón. Muy probablemente el ministro es, en muchas ocasiones, responsable de creerse lo que le dicen sus camaradas cubanos, maestros como son en la propaganda política y en la auto exculpación de las responsabilidades sobre los problemas de la isla.

\footnotetext{
7 Pablo Stefanoni: "La izquierda latinoamericana frente a Venezuela", Nueva Sociedad, febrero 2020, vid. https://nuso.org/articulo/izquierda-Venezuela-Chavez-Maduro/

8 El Periódico, 19.01.2020. https://www.elperiodico.com/es/politica/20200119/pp-marcajepodemos-minuto-cero-7810904
} 
En este caso, sin embargo, el suyo es un error propio, y de bulto. Efectivamente, Cuba figura en la lista de países según el Índice de Desarrollo Humano (IDH) de 2018 en el puesto 73, en el segundo pelotón de estados, el que Naciones Unidas etiqueta como países de Desarrollo Humano Alto. Cuba se encuentra por delante de, por ejemplo, México (74) y Brasil (79); no obstante, está por detrás de Irán (60), Costa Rica (63) o Albania (68). En el primer pelotón, no obstante, hay cincuenta y nueve países, encabezados por Noruega, con España en el lugar 26, Chile (44), Argentina (46) o Uruguay (55) ${ }^{9}$.

Así pues, cuando el joven ministro afirmaba que Cuba tiene un Desarrollo Humano Alto técnicamente no miente, pues así lo clasifica el PNUD, pero la etiqueta induce a engaño si no se advierte que hay seis decenas de países que tienen un IDH Muy Alto, lo que obliga a matizar la rotunda afirmación del joven líder de Izquierda Unida. Ahora bien, lo del "modelo de consumo sostenible" entra ya en el apartado del humor negro. Los cubanos de a pie llevan a estas alturas sesenta años con una cartilla de racionamiento que apenas les permite sobrevivir una parte del mes.

Es cierto que el endurecimiento del embargo norteamericano decretado por Donald Trump ha empeorado la situación de $\mathrm{Cuba}^{10}$, pero Alberto Garzón es un muy buen ejemplo de cómo buena parte de las izquierdas españolas se niegan a aceptar algo que desde el análisis histórico se ha escrito hace más de veinte años: que la revolución social experimentada por Cuba en 1959 entró en una crisis mantenida e irreversible desde la desaparición de la Unión Soviética ${ }^{11}$.

Venezuela, por su parte, aparece en el escenario político español cada vez que el bloque conservador considera que es oportuno para sus intereses, y eso ocurre con mucha frecuencia ${ }^{12}$. Se la usa como arma de agresión, de desgaste del gobierno y -en esta etapa- de la figura de Pedro Sánchez, al que consideran subordinado a su socio Pablo Iglesias.

\footnotetext{
9 Según se explica en el Informe Índices e indicadores de desarrollo humano. Actualización estadística de 2018, que publica PNUD: "Las clasificaciones del IDH se basan en puntos de corte fijos del IDH, que se derivan de los cuartiles de las distribuciones de indicadores de los componentes. Los puntos de corte se establecen en valores del IDH inferiores a 0,550 para el desarrollo humano bajo, de 0,550 a 0,699 para el desarrollo humano medio, de 0,700 a 0,799 para el desarrollo humano alto y de 0,800 o superiores para el desarrollo humano muy alto". Para más información consultar http://hdr. undp.org/sites/default/files/2018 human development statistical update es.pdf

10 Eldiario.es, 17.02.2020 https://www.eldiario.es/theguardian/Trump-arremete-misionesmedicas-economia 0 995650637.html

${ }_{11}$ Marifeli Pérez Stable, La Revolución cubana. Orígenes, desarrollo y legado. Madrid, Editorial Colibrí, 1998.

${ }^{12}$ Carlos E. Cué incidía en esta idea: "Tras meses en segundo plano, la oposición ha elegido de nuevo una crisis muy sensible para los españoles como campo de batalla contra el Ejecutivo. Y Sánchez y su ministra de Exteriores, que se estrena prácticamente en política nacional con este asunto, han abierto un espacio para esa crítica al decidir que no sea el presidente, sino González Laya quien este sábado reciba a Guaidó”. El País, 24/01/2020 https://elpais.com/politica/2020/01/24/ actualidad/1579897148 446733.html
} 
En el desarrollo de esa táctica, las relaciones entre el gobierno de Madrid y los de las distintas repúblicas latinoamericanas son con frecuencia munición artillera para el bloque conservador. El incidente de 2019 en La Paz, cuando diplomáticos y policías españoles acudieron de forma poco convencional a la embajada de México ${ }^{13}$, constituyó una evidencia más de esa utilización de las relaciones internacionales como argumento de política interna contra el gobierno de Sánchez.

Seguimos, pues, como siempre. Las derechas con fuego graneado sobre todo lo que se mueve a contrapelo de sus intereses en relación con América Latina. Y las izquierdas, confundiendo deseos y realidad, aquejadas de su incapacidad para superar sus mitos trasnochados, negándose a llamar a las cosas por su nombre cuando supuestos gobiernos de izquierda se ven desnudados por su incapacidad de gestión y por su facilidad para, incluso, recurrir a la violencia para reprimir a sus opositores. Nada nuevo, pues.

En este texto vamos a desarrollar tres breves análisis sobre otras tantas interferencias notables de los últimos tiempos, con su consiguiente uso político partidario, que se han producido desde tres focos distintos de América Latina. Dos de ellos han sido recurrentes, el venezolano y el boliviano, singularmente el primero. El tercero es México, país que se incorporó a la nómina de puntos calientes para la utilización partidista de las derechas tras la elección del presidente Andrés Manuel López Obrador.

\section{Venezuela como arma arrojadiza}

La extremadamente grave crisis que afecta Venezuela no es sino el resultado de años de mala gestión política y económica del gobierno bolivariano, presidido hasta 2013 por Hugo Chávez y desde esa fecha por Nicolás Maduro. El régimen bolivariano hace mucho que es indefendible tanto política, como económica y socialmente. De esta afirmación, sin embargo, no se debe deducir que es posible aplaudir la actuación de la oposición venezolana durante estos años, pero indiscutiblemente la mayor cuota de responsabilidad en la penosa deriva del país corresponde a quienes están en el poder. Especialmente porque lo han ejercido de manera tan autoritaria como arbitraria.

Desde que el comandante Hugo Chávez ganó de manera incontestable las elecciones de 1998, la evolución política de Venezuela ha sido tortuosa. Ya

\footnotetext{
${ }^{13}$ Mientras que el gobierno de Jeanine Áñez acusó a España de enviar a la embajada de México en La Paz a hombres "encapuchados" y "armados", el Ministerio de Exteriores español aseguró que la visita realizada por la encargada de negocios de España "era exclusivamente de cortesía" y negó que intentara sacar a ex ministros de Morales asilados en la residencia de la embajadora mexicana. La Vanguardia, 28.12.2019 https://www.lavanguardia.com/internacional/20191228/472557799749/ bolivia-embajada-mexico-espana-atropello.html
}

Araucaria. Revista Iberoamericana de Filosofia, Politica, Humanidades y Relaciones Internacionales, año $23, \mathrm{n}^{\circ} 46$. Primer cuatrimestre de 2021. Pp. 173-194. ISSN 1575-6823 e-ISSN 2340-2199 https://dx.doi.org/10.12795/araucaria.2021.i46.09 
en 2002 hubo un auténtico golpe de Estado, rápidamente reconocido por los Estados Unidos de América y por el gobierno español presidido por José María Aznar, que convirtió en presidente al empresario Pedro Carmona. La cosa duró unas horas solamente. Chávez volvió rápidamente al Palacio de Miraflores y la imagen y el prestigio de España quedaron seriamente dañados. Chávez acusó a Aznar de ser uno de los promotores de la intentona de Carmona, mientras que el español se instaló en un discurso de confrontación total contra el venezolano y su gobierno, en el que se mantiene actualmente el Partido Popular. Ya durante la presidencia de José Luis Rodríguez Zapatero, vendría el célebre "¿Por qué no te callas?" de Juan Carlos I a Hugo Chávez en la XVII Cumbre Iberoamericana de Jefes de Estado y de Gobierno realizada en Santiago de Chile en 2007. El líder bolivariano había calificado a Aznar de fascista, y el monarca profirió la lamentable frase mientras Zapatero pedía a Chávez respeto a la figura del expresidente español ${ }^{14}$.

Venezuela, hay que recordarlo, celebra elecciones legislativas y presidenciales, diferenciadas, como ocurre en los países con sistema presidencialista. Pues bien, ya en 2005 la oposición no se presentó a las elecciones a la Asamblea Nacional, como ocurrió en 2018 en las presidenciales. Chávez ganó éstas en 2006 y en 2013, cada vez con menos margen. Poco después de esta última, el Comandante murió de cáncer y fue sustituido por Nicolás Maduro, el cual tuvo que revalidar su presidencia con unas nuevas elecciones que ganó por un ajustadísimo 50.6 frente a un 49.1 del líder opositor Henrique Capriles.

El bolivarianismo venezolano, como siempre ha hecho el populismo latinoamericano, estableció que había un nosotros y un ellos, los buenos revolucionarios patrióticos bolivarianos y los perversos fascistas pagados por el imperialismo; práctica deudora de la lógica primaria que ya estableciera Fidel Castro en 1971, durante su visita al Chile de Allende y la Unidad Popular ${ }^{15}$. El país se había roto justamente por la mitad, pero esto no pareció importarle a Nicolás Maduro, y de esa negativa a reconocer la realidad, a aceptarla y a actuar en consecuencia, provienen muchos de los problemas de hoy.

Pero la realidad es tozuda, y en las elecciones legislativas de 2015 para renovar la Asamblea Nacional la oposición reunida en la Mesa de Unidad Democrática obtuvo el 56.3 por ciento de los votos y 112 de los 167 diputados. La respuesta del gobierno de Maduro fue continuar huyendo hacia delante: el Tribunal Superior de Justicia declaró en desacato a la Asamblea Nacional en 2016 y en 2017 decidió asumir sus funciones. Aunque se dio marcha atrás en esta decisión insólita, la Asamblea Nacional quedó, en la práctica, inoperativa.

\footnotetext{
${ }^{14}$ https://www.youtube.com/watch?v=wizlL5acKEM

15 Vid. Joan del Alcàzar, Chile en la pantalla. Cine para escribir y para enseñar la historia (19701998), Valencia/Santiago, PUV/Centro de Investigaciones D. Barros Arana, 2013.
} 
Las elecciones presidenciales de mayo de 2018, con la abstención más alta en la historia de ese tipo de comicios desde la llegada de la democracia en 1958, dio como resultado la victoria de Maduro con el 67.8 por ciento de los votos emitidos. Sin embargo, diversos organismos presentaron denuncias por falta de transparencia en el proceso de convocatoria y realización, además de por parcialidad del poder electoral. La crítica internacional provocó que, en enero de 2019, ante la toma de posesión de Nicolás Maduro, ni los países del Grupo de Lima, ni la Unión Europea, ni la Organización de Estados Americanos reconocieran al mandatario.

Que el presidente electo no jurara el cargo ante la Asamblea Nacional fue el argumento que hizo valer Juan Guaidó para autonombrarse presidente, alegando que había un vacío de poder. Ahora está prácticamente desaparecido, pero durante semanas, Venezuela contó, cuanto menos en el escenario internacional, con dos presidentes reconocidos por unos o por otros países.

La crónica de un desastre anunciado, pues, ha sido la evolución política venezolana desde hace años.

En cuanto a la deriva económica y social, ya hemos escrito en varias ocasiones ${ }^{16}$. En concreto en marzo de 2015, es decir hace un lustro, ya sabíamos lo mal que iba la economía y padecíamos una falta de información estadística oficial casi total ${ }^{17}$. De hecho, en el Informe publicado por la Comisión Económica para América Latina (CEPAL) sobre Gasto Social en América Latina (2000-2016) se insiste en que Cuba, Haití y la República Bolivariana de Venezuela no facilitan datos en varios importantes ítems de los recogidos en el informe.

En el citado texto de 2015 se puede leer: Venezuela ya no ofrece según qué estadísticas internas; el bono venezolano está en la categoría de bono basura, el PIB de 2014 fue de -3\%; y una última y fundamental: en 1998, la proporción entre exportaciones petroleras y no petroleras era 69 a 31 mientras que en 2012 fue de 96 a 4 . Y esto con un precio del barril en torno a los 55 dólares $^{18}$. En cuanto a la débil institucionalidad, ésta se hace evidente en la pasión legisladora del gobierno: todo se regula, pero nada o casi nada funciona en las instituciones, en las que prevalece tenerlas al servicio de la revolución. Un botón de muestra: de las 45.474 sentencias emitidas desde instancias judiciales, ni una sola ha sido en contra del gobierno ${ }^{19}$. Finalmente, con respecto a la fractura de los cuerpos de seguridad, hay que apuntar que después de la creación de unos y

\footnotetext{
16 Joan del Alcàzar "La imposible cubanización de Venezuela" en Miriada Hispánica, University of Virginia, $\mathrm{n}^{\mathrm{o}} 15,2017$, pp. 29-54.

17 Joan del Alcàzar "Petróleo, Venezuela, Cuba. Negros nubarrones cubren el horizonte del luminoso Caribe", (2015), Foro mexicano Colloqui. http:/www.colloqui.org/colloqui/2015/5/3/ petrleo-venezuela-cuba-negros-nubarrones-cubren-el-horizonte-del-luminoso-caribe

${ }^{18}$ Ídem.

${ }^{19}$ Román Ortiz: "Venezuela: la tormenta perfecta", PDUH-UNAM, 2014. http://www.pudh.unam. $\underline{\mathrm{mx} / \text { perseo/venezuela-la-tormenta-perfecta/ }}$
}

Araucaria. Revista Iberoamericana de Filosofia, Politica, Humanidades y Relaciones Internacionales, año $23, \mathrm{n}^{\circ} 46$. Primer cuatrimestre de 2021. Pp. 173-194. ISSN 1575-6823 e-ISSN 2340-2199 https://dx.doi.org/10.12795/araucaria.2021.i46.09 
la remodelación de otros preexistentes, conviven en el interior del país ocho estructuras militares y policiales de ámbito nacional, a las que hay que sumar las de los estados y las de los municipios. En este terreno, las rivalidades entre unas y otras son moneda corriente, y la gran paradoja final es que son las empresas de seguridad privadas [nada convencionales, por cierto] las que han salido beneficiadas en un país que tiene las tasas de violencia más altas del continente sólo por detrás de Honduras y el Salvador, y en el que Caracas es la ciudad con mayor índice de homicidios por cada cien mil habitantes, después de San Pedro Sula (Honduras) y Acapulco (México) ${ }^{20}$.

La situación económica ha ido a peor desde 2015 a esta parte. El Fondo Monetario Internacional (FMI) incluyó a Venezuela, en octubre de 2018, entre las grandes crisis económicas del siglo XXI, un listado dominado por países que han sufrido conflictos bélicos. Según el FMI ${ }^{21}$, la caída del PIB por habitante entre 2013 y 2017 fue del 37 por ciento; además, las previsiones para el periodo 2012-2019 eran del -47\%. El PIB por habitante de Venezuela ha pasado de los 11.287 dólares de 2012 a los 3.100; es decir, un hundimiento del 73\%, siempre según los datos del FMI.

Según escribe el historiador venezolano Tomás Straka ${ }^{22}$, las calles de su país han estado muy movidas en contra de Maduro. En lo que es la coronación de una tendencia que ya se preveía desde 2017, esta vez el mayor protagonismo de las protestas ha sido en los barrios populares. Con una hiperinflación de $1.000 .000 \%$ en 2018 y una depreciación del bolívar que ha llevado el sueldo mínimo a unos siete dólares mensuales, el hambre ha terminado para impulsar el disgusto de los venezolanos pobres que por una u otra razón no han podido, o no han querido, unirse a la masa de migrantes que se desborda por toda Sudamérica. Según escribía Straka en 2019: "Desde hace días, los barrios pobres de Caracas y otras varias ciudades se han convertido en escenario de verdaderas batallas campales. Ha habido saqueos, pero también actos de claro tinte político, como la quema de casas del Partido Socialista Unido de Venezuela (PSUV) o el derribo de estatuas de Hugo Chávez"23.

La híperpolarización política interna de una parte, y el reparto de apoyos externos a favor y en contra de Nicolás Maduro o de Juan Guaidó, reproducen el patrón de esta Segunda Guerra Fría de la que cada vez se habla más. En ella,

\footnotetext{
${ }^{20}$ Datos de la Oficina de la ONU contra la Droga y el Delito, 2012. Vid. https://www.unodc.org/ unodc/es/index.html

${ }^{21}$ Según datos del FMI, la lista de países que más PIB per cápita han destruido en este siglo está encabezada por Yemen, quien entre los años 2000-2017 observó cómo este indicador se contraía en un 70\%. Le sigue Libia con una pérdida del 62\% de su PIB entre los años 2010-2011; continúa Sudan del Sur con un descenso del 54\% entre el 2011-2012 y en el cuarto puesto tenemos a Venezuela con una destrucción sostenida y ascendente de su PIB. Cinco Días, 25.01.2019, https://cincodias.elpais.com/cincodias/2019/01/25/economia/1548423787 186188.html

${ }^{22}$ Tomás Straka: "Urgente, Venezuela”, Revista Nueva Sociedad, enero 2019, https://nuso.org/ articulo/urgente-venezuela/?utm_source=email\&utm medium=email

${ }^{23}$ Ídem.
}

Araucaria. Revista Iberoamericana de Filosofia, Politica, Humanidades y Relaciones Internacionales, año $23, \mathrm{n}^{\circ} 46$. Primer cuatrimestre de 2021. Pp. 173-194. ISSN 1575-6823 e-ISSN 2340-2199 https://dx.doi.org/10.12795/araucaria.2021.i46.09 
el enfrentamiento por el control de las reservas energéticas es un eje central, y ahí están los Estados Unidos, China y Rusia. Los primeros con poderosos aliados continentales como Brasil, Argentina y Canadá; o el Reino Unido en el exterior. Enfrente de este bloque, China y Rusia con Turquía, Cuba y el resto de los países llamados bolivarianos.

El problema Venezuela interesa y mucho en todo el mundo. En España, el Partido Popular y Ciudadanos han decidido competir también en este terreno, y sus líderes hacen declaraciones periódicas, se reúnen con exiliados y acusan al gobierno de Sánchez de ser, prácticamente, el causante de la crisis de aquel país latinoamericano. Además, Venezuela es el ariete preferido del bloque conservador para embestir al partido Podemos, el socio minoritario del gobierno que lidera Pedro Sánchez.

Hay que decir, sin embargo, que en la competición de los dos partidos de la derecha española por ser el más beligerante, es el partido Popular de Pablo Casado el que lleva ventaja. El expresidente Aznar denuncia con frecuencia en los medios de comunicación el "abandono de liderazgo lamentable" de Pedro Sánchez, y le acusa de falta de reflejos con este tema. A su juicio, esa carencia se debe al hecho de no tener ni "criterio" ni "convicción" en política exterior y en cuanto al papel de España en la UE ${ }^{24}$.

El llamado Trío de Colón [PP, Vox y Ciudadanos, las tres derechas españolas] se refiere al actual gobierno como una "coalición social-comunista y bolivariana", en la explotación de una veta que descubrieron hace años para intentar desacreditar especialmente a Podemos: la de una supuesta financiación ilegal de este partido procedente de Caracas. Aunque los tribunales, hasta el Supremo, han desechado en repetidas ocasiones las acusaciones de los conservadores, ellos siguen con sus acusaciones en este sentido ${ }^{25}$.

Pese a que, desde marzo de 2020, la pandemia mundial ha puesto sordina al problema internacional venezolano, que solo emerge en momentos particulares, en España el PP sigue utilizándolo en su campaña de acoso al gobierno de Pedro Sánchez, al tiempo que intenta conjurar también sus problemas internos y la competencia electoral de Vox. Venezuela ha sido convertida, en la práctica, en un problema interno español en la medida que sirve para la confrontación partidaria doméstica.

\footnotetext{
24 Además, Aznar acusó a Zapatero de intentar consolidar a Nicolás Maduro. Elplural.com, 25.01.19, https://www.elplural.com/politica/jose-maria-aznar-carga-contra-pedro-sanchez-porvenezuela_209988102

25 "Desde su nacimiento, Podemos ha sido acusado de diferentes delitos mediante querellas judiciales sonadas". En total, hasta el momento han sido al menos catorce las querellas archivadas por los tribunales dirigidas contra el partido liderado por Pablo Iglesias o contra alguno de sus dirigentes". Nota de prensa en el periódico Cuartopoder, 12.03.2017, https://www.cuartopoder.es/ espana/2017/03/12/la-justicia-ha-archivado-ya-14-querellas-podemos-dirigentes/
} 


\section{El presidente mexicano excitó a las derechas hispánicas}

El presidente mexicano, Andrés Manuel López Obrador, AMLO tanto para amigos como para adversarios, publicó una pequeña intervención grabada en vídeo -el 25 de marzo de 2019²6 - en la que pedía que el Rey de España ofrezca sus disculpas a los descendientes de los pobladores originarios de lo que hoy es su país; y esto por los horrores de la conquista que comenzó Hernán Cortés.

Visto el incidente con cierta perspectiva, entendemos que la situación generada por el mandatario mexicano puede abordarse desde dos planos: el que llamaríamos histórico y el que podríamos denominar estrictamente político. En cuanto al primero, pensamos que la intervención de AMLO fue confusa sintetizando al máximo y dejando de lado cuestiones secundarias- en la medida que mezcló la conquista propiamente dicha, la independencia, el Porfiriato y la Revolución mexicana sin solución de continuidad.

Tal vez alarmado por la virulencia de una parte de las respuestas que provocó - desde España y también desde México-, López Obrador enfatizó en una intervención posterior que también él, en nombre del Estado mexicano, ofrecería esas disculpas por la parte que corresponde a los siglos XIX y XX, ahora que se acerca el bicentenario de la independencia del país ${ }^{27}$.

Partimos de la base de que no es posible reescribir la historia y que no tiene demasiado sentido revisar un proceso traumático vivido hace cinco siglos con categorías del presente. Complementariamente, desde esa misma lógica, pensamos que hablar de Derechos Humanos en relación con la conquista, que indiscutiblemente fue muy cruenta y causó un sinfín de sufrimiento, no es adecuado.

Sin embargo, no debiera ser difícil que la diplomacia española y la mexicana llegaran a consensuar una declaración conjunta que reconociera que la conquista fue un proceso terrible, particularmente para los pobladores originarios. Podría reconocerse que el 12 de octubre no hay nada que celebrar, como se dice desde las posiciones más aguerridas cuando se juzga la irrupción de los europeos en el continente americano, aunque no está de más conmemorar la efeméride, en tanto que -guste más o menos- es, a no dudar, una fecha emblemática.

En cuanto al plano político, el de AMLO resultó ser un discurso de consumo fundamentalmente interno, ante el que cabe preguntarse si más allá de una respuesta española en sintonía con lo exigido en política de gestos,

\footnotetext{
${ }^{26}$ Vídeo en el que el presidente de México López Obrador, pide al Rey de España que se disculpe por los abusos de la conquista. https://www.youtube.com/watch?v=QXSvRJIYRwI

27 Frente a las diversas respuestas que recibió desde España el presidente de México, López Obrador afirmó en una comparecencia posterior que no quería enfrentarse a España. http://www.rtve. es/alacarta/audios/las-mananas-de-rne-con-inigo-alfonso/presidente-mexico-insiste-disculpa-peromatiza/5096348/
}

Araucaria. Revista Iberoamericana de Filosofía, Política, Humanidades y Relaciones Internacionales, año $23, \mathrm{n}^{\circ} 46$. Primer cuatrimestre de 2021. Pp. 173-194. ISSN 1575-6823 e-ISSN 2340-2199 https://dx.doi.org/10.12795/araucaria.2021.i46.09 
lo más urgente para muchos de los actuales descendientes de los pobladores originarios sería tomar medidas políticas inclusivas y efectivas que reduzcan se forma significativa la extrema pobreza que padecen. No tienen porqué ser soluciones alternativas, sino que podrían tejerse de forma paralela.

En un segundo momento debemos atender a cómo reaccionaron las derechas hispanas, cargadas de ese nacionalismo al que llaman patriotismo, ante la petición de AMLO. Más allá de determinadas declaraciones subidas de tono, inadmisibles y auto-descalificadoras por insultantes y denigrantes, dirigidas al presidente mexicano (el escritor Pérez Reverte, por ejemplo), los políticos españoles respondieron según un esquema perfectamente previsible. El PP, Ciudadanos y Vox, con Pablo Casado, Albert Rivera y Santiago Abascal, respondieron más que airadamente ${ }^{28}$. Calificaron las palabras de López Obrador de ofensivas y coincidieron en que si alguien debía disculparse había de ser, precisamente, el mandatario mexicano. Todo ello tras remarcar que la tarea de España en América fue "un hito en la historia de la Humanidad de la que todos [los españoles] debemos estar muy orgullosos" [sic].

En cuanto a la respuesta de Podemos tampoco hubo sorpresas. Ione Belarra, por ejemplo, usó Twitter para afirmar que López Obrador tiene mucha razón en exigirle al rey que pida perdón por los abusos de la Conquista. Y añadió que cuando gobierne Podemos (en solitario, se supone) "habrá un proceso de recuperación de la memoria democrática y colonial que restaure a las víctimas" [sic]. Desde el PSOE, más allá de alguna voz desafinada, primó la posición del Gobierno de Pedro Sánchez, también con un tono y con unos contenidos previsibles, pero más respetuosos y constructivos ${ }^{29}$.

Más allá de las respuestas partidarias y de la del Gobierno de Madrid, el actual gobierno mexicano sabe que la derecha española nacionalista y reaccionaria carece de la sensibilidad necesaria para responder de forma edificante a una petición como la que formuló, más allá de que podamos discutir

\footnotetext{
${ }^{28}$ Un par de ejemplos que ilustran esto que decimos. Vía Twitter, el escritor y académico de la RAE llegó a insultar al presidente mexicano: "Que se disculpe él, que tiene apellidos españoles y vive allí. Si este individuo se cree de verdad lo que dice, es un imbécil. Si no se lo cree, es un sinvergüenza". El líder del PP, por su parte, arremetió con dureza contra el "amigo izquierdista de Pedro Sánchez" y la prensa recogió declaraciones que expresan con claridad las posiciones de la derecha española respecto a lo dicho por AMLO: "Lo que ha dicho es una afrenta para España. Que venga a decir que España hizo toda clases de barbaridades en ese país hermano es algo que yo no voy a permitir" [...]El Gobierno de España tiene que decir claramente a este tipo de gobiernos izquierdistas que no compartimos esas palabras". El diario El País informaba que "el dirigente popular ha aprovechado para reivindicar su visión sobre la importancia del descubrimiento de América y la representación histórica de España en ese continente, que ya expresó el pasado 12 de octubre en Málaga: Yo no creo en la leyenda negra ni en la que la izquierda acomplejada. Somos una de las naciones más importantes de la humanidad", $E l$ Pais, 26.03.19, https://elpais.com/politica/2019/03/26/actualidad/1553595074_910466.html

${ }^{29}$ No obstante, el mismo diario enfatizó que el ministro de Exteriores había puesto el acento en que "hay que mantener la mejor relación entre los pueblos y el Gobierno español y mexicano por las profundas relaciones que les unen”, La Razón 26.03.19, https://www.larazon.es/espana/carmen-calvoadvierte-a-lopez-obrador-de-que-espana-no-tiene-que-pedir-perdon-a-ningun-pais-LN22581318/
} 
si la forma en la que lo hizo fue la más adecuada. Si las derechas hispánicas no se han mostrado sensibles ante las peticiones de los familiares de los miles de víctimas de la guerra de España que aún permanecen en las cunetas, ochenta años después, nadie debería sorprenderse por la respuesta a la demanda de reparación por los horrores de la conquista americana de hace cinco siglos.

México es un país con el que España tiene unos lazos tan fuertes como incuestionables $\mathrm{y}$, efectivamente, tiene una deuda histórica indiscutible: la derivada de la fraterna y solidaria acogida a miles de fugitivos de la Guerra Civil y de la dictadura de Franco. En estos tiempos, cuando se han cumplido 80 años de aquella recepción a miles de exiliados españoles, es un tiempo idóneo para poner el énfasis en lo que une a ambos países, como sociedades de ciudadanos libres y con memoria histórica, y abordar lo que son cicatrices de las heridas del pasado, tan remotas como el siglo XVI, pero con la firme voluntad de superarlas.

\section{¿A quién le importa Bolivia?}

Evo Morales, el primer presidente aymara de la historia de los países andinos renunció a su cargo el 10 de noviembre de 2019, y se marchó al exilio mexicano acogido por su colega A.M. López Obrador. El detonante final de la caída de Morales fue que el Ejército boliviano "sugirió" al presidente que abandonara el cargo, y esto en medio de un clima de tensión y violencia creciente.

Está en discusión si esto fue o no un golpe de Estado propiciado por los militares, tan frecuentes como han sido en la historia del país. No se ha tratado de un pronunciamiento convencional, con las tropas y los carros de combate en las calles, pero sí es cierto que las fuerzas armadas no han cumplido con su papel de garantizar la legalidad constitucional republicana. Sorprende, además, la mansa y aséptica respuesta de la comunidad internacional: desde la Organización de Estados Americanos a la Unión Europea, que aceptaron de facto a la nueva presidenta autonombrada, Jeanine Áñez. Huelga decir que los Estados Unidos de Trump y el Brasil de Bolsonaro la recibieron con los brazos abiertos.

Esta abogada y presentadora de televisión que se dio a conocer internacionalmente entrando en el parlamento con una Biblia de tamaño gigantesco, y que ha hecho declaraciones que van del racismo y el integrismo religioso a la negación de los principios elementales de la democracia, refuerza la tesis de que lo que ha habido en Bolivia ha sido, efectivamente, un golpe de estado institucional con el visto bueno de los militares y la policía. Áñez no sólo no convocó de inmediato nuevas elecciones, es que se negó a abrir 
un imprescindible diálogo con el partido de Morales, el MAS, que había sido el ganador de las últimas elecciones, ni con Carlos Mesa, que era el segundo candidato a la presidencia. Con extrema urgencia, procedió a relevar a la mayoría de los embajadores de Bolivia y comenzó a revertir el marco económico legal establecido durante los años de Evo Morales.

Con todo, la medida más polémica fue la de exonerar a priori a las fuerzas armadas y a la policía de cualquier actuación violenta que pudieran realizar en la represión de las protestas populares protagonizadas por los partidarios de Morales.

El ahora expresidente tomó posesión del cargo en enero de $2006^{30}$. Su intervención en el solemne acto se desarrolló en un doble plano: el primero, centrado en ensalzar sus raíces originarias y a comprometerse con los principios básicos de la ley de sus antepasados; el segundo, dedicado a anunciar los objetivos centrales de su gobierno, que se concretaban en "una segunda independencia de Bolivia mediante un nuevo pacto social".

Morales comenzó aquel acto pidiendo un minuto de silencio por los Mártires de la Liberación [indígena], citando por su nombre a los más reconocidos héroes de su mitología, desde Tupac Amaru, Tupaj Katari o Bartolina Sisa, a otros más recientes y universales como el Che Guevara, el socialista boliviano Marcelo Quiroga y el jesuita catalán Lluís Espinal, asesinados los dos últimos durante el golpe militar de García Meza en 1980. El discurso terminó con una deferencia para con el entonces líder del EZLN mexicano: "Cumpliré con mi compromiso, como dice el Subcomandante Marcos, mandaré obedeciendo al pueblo, mandaré [en] Bolivia obedeciendo a mi pueblo".

No hay que olvidar que el pueblo del que hablaba el presidente Morales es mayoritariamente descendiente de los pobladores originarios, y son muchos los agravios que han sufrido, como recordó en su primer discurso: "Los pueblos indígenas, que son mayoría de la población boliviana: el 62.2\% de aymaras, de quechuas, de mojeños, de chipayas, de mulatos, de guaraníes. Estos pueblos, históricamente hemos sido marginados, humillados, odiados, despreciados, condenados a la extinción. Esa es nuestra historia; a estos pueblos nunca los reconocieron como seres humanos, siendo que estos pueblos son los dueños absolutos de esta noble tierra, de sus recursos naturales" ${ }^{31}$.

Evo Morales, además, aprovechó la ocasión para anunciar que, a partir de entonces, "las cosas han comenzado a cambiar". Transmitió a los asistentes una vivencia personal: "Esta mañana, esta madrugada, con mucha alegría he visto algunos hermanos y hermanas cantando en la plaza histórica de Murillo, la Plaza Murillo como también la Plaza San Francisco, cuando hace 40, 50 años

\footnotetext{
${ }^{30}$ Joan del Alcàzar "Indigenisme, democràcia i pacte social" en L'Espill, Segona Època, (2006) Número 23, pp. 34-43.

31 Primer discurso del expresidente Evo Morales, 22.01.2006. http://democraciasur. com/2006/01/29/discurso-de-evo-morales-al-asumir-la-presidencia-de-bolivia/
} 
no teníamos derecho a entrar en la Plaza San Francisco, en la Plaza Murillo. Hace 40, 50 años no tenían nuestros antepasados el derecho de caminar por las aceras. Esta es nuestra historia, esta nuestra vivencia" ${ }^{\prime 2}$.

El nuevo presidente aprovechó para denunciar el apartheid en versión criolla en el que ha vivido la mayoría de los bolivianos, pero esto -anunció en el ahora lejano 2006- iba a cambiar pronto, aunque nadie les regalaría nada: "Bolivia parece Sudáfrica. Amenazados, condenados al exterminio estamos aquí, estamos presentes. Quiero decirles que todavía hay resabios de esa gente que es enemiga de los pueblos indígenas, queremos vivir en igualdad de condiciones con ellos, y por eso estamos aquí para cambiar nuestra historia, este movimiento indígena originario no es concesión de nadie; nadie nos lo ha regalado, es la conciencia de mi pueblo, de nuestro pueblo"33.

No será fácil, dijo Morales en su discurso: “¿Cómo buscar mecanismos que permitan reparar los daños de 500 años de saqueo a nuestros recursos naturales? Será otra tarea que implementaremos en nuestro gobierno [...] queremos cambiar Bolivia no con bala sino con voto, y esa es la revolución democrática".

Aquella "revolución democrática" prometida en 2006 ha tenido luces y sombras. Según diversos organismos internacionales, la economía de Bolivia ha experimentado una transformación estructural durante la presidencia de Evo Morales. El PIB real por cápita creció en más de un 50\%, lo que equivale al doble de la tasa de América Latina. Durante la mayor parte de los últimos 13 años, Bolivia ha tenido superávit en la balanza de pagos, lo que ayudó a mantener la estabilidad macroeconómica, y esto ha contribuido sustancialmente a la reducción de la pobreza y la indigencia. La primera ha caído por debajo del $35 \%$ (cuando estaba en el $60 \%$ en 2006) y la tasa de pobreza extrema es del $15.2 \%$ (cuando estaba en el $37.7 \%$ en 2006$)^{34}$.

La transformación económica de Bolivia fue posible gracias a un conjunto de importantes modificaciones políticas en el país: desde una nueva Constitución a la nacionalización y propiedad pública de recursos naturales y de algunos sectores estratégicos de la economía, entre los que destaca la enorme importancia de la nacionalización de los hidrocarburos.

Todo, sin embargo, no son éxitos. También hay que considerar los déficits de los años de Evo Morales, que no son pocos. El más reciente es, precisamente, el que tiene que ver con el inmediato pasado, el de los últimos meses, el que ha pivotado sobre el proceso de reelección del ahora exiliado presidente.

$\mathrm{Su}$ imagen viró para muchos a negativa desde el 21 de febrero de 2016, cuando sufrió la primera derrota electoral y decidió no aceptarla. Perdió un

${ }^{32}$ Ídem.

${ }^{33}$ Ídem.

${ }^{34}$ El Financiero 29.01.2006, http://democraciasur.com/2006/01/29/discurso-de-evo-morales-alasumir-la-presidencia-de-bolivia/

Araucaria. Revista Iberoamericana de Filosofia, Política, Humanidades y Relaciones Internacionales, año $23, \mathrm{n}^{\circ} 46$. Primer cuatrimestre de 2021. Pp. 173-194. ISSN 1575-6823 e-ISSN 2340-2199 https://dx.doi.org/10.12795/araucaria.2021.i46.09 
referéndum que había convocado para modificar la Constitución, con el fin de poder presentarse a las elecciones previstas para 2019. Venció al NO. El 51\% de los bolivianos le dijo que no estaba de acuerdo ${ }^{35}$.

En realidad, Morales ya había agotado tres mandatos presidenciales, y no dos como limita la Constitución, pero él y los suyos siempre han argumentado que el primero, de 2006 a 2009, no debía contabilizarse porque fue a raíz de la aprobación de la nueva carta magna, la del Estado Plurinacional, cuando los periodos presidenciales debían comenzar a contar.

Aun así, al perder el referéndum de 2016 Morales presentó un recurso al Tribunal Constitucional, el cual autorizó en 2017 su candidatura con el surrealista argumento de que limitar el número de mandatos presidenciales suponía atentar contra lo dispuesto en la Convención Americana de los Derechos Humanos. Para muchos, aquí comenzó el principio del fin de Evo Morales.

Sin embargo, un experto reconocido de la realidad social y política de la Bolivia reciente como es Bartolomé Clavero $^{36}$ explica que, desde hace más años, desde el inicio de la segunda década del nuevo milenio, las cosas empezaron a torcerse drásticamente para los bolivianos. Mediante los cambios ministeriales oportunos, el Gobierno canceló su programa de reconducción comunitaria, entrando en connivencia con los "comités cívicos" (asociaciones de organizaciones empresariales y vecinales, dirigidas por élites locales, que se ocupan de reivindicaciones particulares) aunque mantenía la habitual retórica indigenista. Adoptó una política explícita de favorecer intereses corporativos internacionales, especialmente en cuanto a industrias extractivas. En suma, comenzó a desviarse de manera constatable de la Constitución, pero sin cambiar ni una sola coma de ella.

Lógicamente tropezó con resistencias, en particular por parte de organizaciones indígenas y sindicales. El Pacto de Unidad se rompió en 2011, permaneciendo en él tan sólo aquellas entidades aceptadas por el MAS, el partido oficialista. La respuesta de Evo Morales, de su Gobierno y de sus organizaciones afines ha estado caracterizada por el hostigamiento, la cooptación y la corrupción. El Gobierno modificó las condiciones de acceso de empresas internacionales a los recursos de Bolivia, consiguiendo unos fondos que han abonado la corrupción y el clientelismo. Sin embargo -luces y sombras-, estos recursos también se han utilizado para desarrollar políticas sociales beneficiosas para una parte relevante de la ciudadanía. Además, como

\footnotetext{
35 En aquel entonces, la derrota de Morales no trajo consigo una alternativa a su gobierno por parte de la oposición. El País 24.02.2016 https://elpais.com/internacional/2016/02/24/ actualidad/1456274986_514912.html

${ }^{36}$ En el artículo "Bolivia, de plurinacional a cívica" publicado en el blog Conversación sobre la Historia (2019), Bartolomé Clavero explica, además, el drástico cambio que comenzó a observarse en los campos bolivianos.https://conversacionsobrehistoria.info/2019/11/17/bolivia-de-plurinacionala-civica/?fbclid=IwAR3pEcJSZqdLDikHW4LVGIWTTONkBWcrBOgQzeXSh8gA6Fq2VT1X4 ip iEw
}

Araucaria. Revista Iberoamericana de Filosofia, Política, Humanidades y Relaciones Internacionales, año $23, \mathrm{n}^{\circ} 46$. Primer cuatrimestre de 2021. Pp. 173-194. ISSN 1575-6823 e-ISSN 2340-2199 https://dx.doi.org/10.12795/araucaria.2021.i46.09 
concluye Clavero, su indigenismo no sólo ha sido retórico e insidioso, sino que también es cierto que -luces y sombras de nuevo- se han puesto en práctica políticas antirracistas que han provocado un cambio cultural profundo en la sociedad boliviana.

La figura de Evo Morales, sin embargo, está en cuestión también por otras prácticas inaceptables desde parámetros democráticos. Rita Segato, la antropóloga y feminista argentina ha sido muy dura con el expresidente: "Cayó por su propio peso, por un vacío de poder que se generó por sus muchos errores y excesos" "37.

Además de por forzar su reelección de manera antidemocrática, de espaldas al resultado del referéndum de 2016, Segato critica a Morales por su actitud frente a problemas medioambientales, tales como los incendios forestales en el bosque Chiquitano, cuando se comportó igual que el brasileño Jair Bolsonaro ante los incendios de la Amazonia. Una actitud similar a la que el mandatario tuvo en torno a la construcción de la autopista que partiría en dos una selva muy rica en biodiversidad que es, al mismo tiempo, un área indígena y una reserva ecológica: "Nos dejó a todos absolutamente perplejos por su negativa a negociar con las comunidades indígenas".

Una perplejidad que pasa a indignación ante el machismo que Segato denuncia en el expresidente, quien al hablar de cuando le llegue la hora de retirarse dijo que lo haría: "con mi charango, con mi coca y con mi quinceañera". Una forma de razonar que refuerza los rasgos del duro machismo imperante en Bolivia, que "delata el autoritarismo de un gobernante [...] y la pretensión de estar por encima del bien y del mal [por qué] la agresión verbal, física, psicológica y moral a las mujeres es una agresión política que delata la voluntad de poder" 38 .

Coincidimos con Clavero cuando dice que la discusión sobre si ha habido o no ha habido golpe de Estado en Bolivia no tiene demasiado sentido. Los que dicen que no, intentan ocultar la ilegitimidad de Jeanine Áñez; mientras que los que dicen que sí pretenden difuminar la responsabilidad de Morales y del MAS. La terca realidad, sin embargo, especialmente en Europa, es que -como afirma Bartolomé Clavero- padecemos "una desinformación pavorosa, en buena parte deliberada, sobre lo que ha pasado en Bolivia,

\footnotetext{
${ }^{37} \mathrm{La}$ antropóloga ofreció un análisis verdaderamente crítico de la izquierda progresista a la que se adscribe. Segato, en su breve entrevista, logra alejarse de los salvoconductos que con tanta frecuencia se usan dentro de la izquierda y que no hacen sino ensombrecer y desacreditar procesos de transformación social. Sin desmerecer la labor de Evo Morales, Segato deja claro que la izquierda no está exenta de la réplica y perpetuación del machismo y de todas sus formas de poder. Que la mala gestión y la arbitrariedad tiene consecuencias provenga de donde provenga. Lo que, como conocemos, en el caso de la izquierda es todavía más severo el castigo social y político cuando se mella la confianza de la población. Radio Deseo de Bolivia, 19.11.2019, https://www.infobae.com/ america/america-latina/2019/11/20/rita-segato-durisima-con-evo-morales-dijo-que-no-fue-victimade-un-golpe-y-recordo-su-machismo-y-autoritarismo/

38 Ídem.
}

Araucaria. Revista Iberoamericana de Filosofia, Politica, Humanidades y Relaciones Internacionales, año $23, \mathrm{n}^{\circ} 46$. Primer cuatrimestre de 2021. Pp. 173-194. ISSN 1575-6823 e-ISSN 2340-2199 https://dx.doi.org/10.12795/araucaria.2021.i46.09 
para lo bueno y para lo malo, para lo mejor y para lo peor, durante la última década y hasta hoy"39.

Por lo que hace a la incidencia de Bolivia en el escenario político y partidario en España es mucho menor que las que hemos visto anteriormente. Bolivia no tiene ni el peso ideológico ni económico de Venezuela o México. No obstante, la figura del presidente Evo Morales le ha otorgado un plus mediático que no se puede obviar, aunque ha predominado una atención a sus formas alejadas de las de otros presidentes, a su atuendo o a su condición de indígena. Tras su abrupta salida de la presidencia de Bolivia, Morales no ha dejado de merecer la atención de la prensa conservadora española, en ocasiones con titulares contundentes basados en especulaciones ${ }^{40}$.

Morales y Bolivia, no obstante, han merecido atención, apoyos o descalificaciones, cuando se les ha vinculado al bolivarianismo, al populismo político, o a la sintonía con la Venezuela chavista o la Cuba castrista ${ }^{41}$. Los vínculos con el partido Podemos y con algunos de sus líderes ha sido utilizada por las derechas como arma de desgaste del partido de Pablo Iglesias, al que se le ha acusado de tener relaciones incluso delictivas con los bolivianos de Evo Morales y su partido ${ }^{42}$.

Tras el abandono de Morales, los partidos políticos españoles discreparon en cuanto a la calificación de golpe de Estado a lo ocurrido en La Paz. Mientras que Podemos afirmó taxativamente que sí lo era y pidió al gobierno de Sánchez que ofreciera asilo político a Morales ${ }^{43}$, el PP, Ciudadanos y Vox lo negaron. Por su parte, el PSOE, buscó una posición mucho más tibia y llegó a solicitar la mediación de la Conferencia Episcopal, Naciones Unidas y la Unión Europea ${ }^{44}$.

\footnotetext{
${ }^{39}$ Bartolome Clavero, Op. Cit.

$40 A B C, \quad 23.08 .2020$ https://www.abc.es/internacional/abci-pedofilia-acosa-bolivia-morales-ycandidato-presidencial-202008230141 noticia.html

${ }^{41}$ De hecho, cuando Evo Morales realizó una visita oficial a España en 2013 fue recibido por el presidente Rajoy en La Moncloa, pero el mandatario del PP se negó a comparecer en rueda de prensa conjunta con el presidente Morales, quien tuvo que verse con la prensa española en un hotel, marcando así una pauta completamente inusual en el terreno diplomático eldiario.es 03.09.2013 https://www. eldiario.es/politica/rajoy-protocolo-evo-morales-moncloa_1 5793116.html

${ }^{42}$ El Mundo, 29.01.2020 https://www.elmundo.es/opinion/2020/01/28/5e2f3193fdddff8240 $\underline{8 \mathrm{~b} 4624 . \mathrm{html}}$

43 Europapres 11.11.2019 https://www.europapress.es/nacional/noticia-podemos-condena-golpeestado-bolivia-pide-gobierno-sanchez-ofrezca-asilo-politico-evo-morales-20191111170236.html

${ }^{44}$ Cuartopoder 24.11.2019 https://www.cuartopoder.es/espana/2019/11/24/podemos-condena-elgolpe-de-estado-en-bolivia-el-pp-lo-niega-y-el-psoe-no-entra-en-la-discusion-terminologica/
}

Araucaria. Revista Iberoamericana de Filosofia, Política, Humanidades y Relaciones Internacionales, año $23, \mathrm{n}^{\circ} 46$. Primer cuatrimestre de 2021. Pp. 173-194. ISSN 1575-6823 e-ISSN 2340-2199 https://dx.doi.org/10.12795/araucaria.2021.i46.09 


\section{Conclusiones}

Pocas realidades sociales y políticas externas generan en España tantas opiniones y posturas partidistas como la de América Latina. En ocasiones despierta simpatía y solidaridad, otras veces recelo y desconfianza, pero, en cualquier caso, siempre genera algún tipo de reacción en la crispada España actual. No es una tierra ajena, no es extraña para los ibéricos. Se trata, como ya sabemos, de una región que conecta con la historia y la cultura española desde hace más de quinientos años. No obstante, puede decirse que la desinformación y el maniqueísmo suelen caracterizar las reacciones o las consecuencias que generan en España las noticias que llegan de América Latina.

Esos vínculos histórico-culturales son utilizados en la política partidaria, tanto por los unos como por los otros (latinoamericanos y españoles). En España, por ejemplo, tal y como hemos observado en los tres casos que hemos atendido (Venezuela, México y Bolivia) se hace un uso indiscriminado de la realidad social y la política de Latinoamérica con fines partidarios, fundamentalmente de desgaste de los oponentes políticos. Se observa cierta malicia en el uso de la información o se manipula en beneficio propio, y se convierte cualquier acontecimiento en un arma contra el adversario político. Todo ello sin importar los efectos colaterales que provocan el impacto mediático de las declaraciones de los líderes de los partidos más importantes de España. Para los políticos españoles, muy especialmente los conservadores, América Latina es un arsenal de munición para el uso partidista según convenga.

No obstante, puede decirse que de esta práctica no escapa nadie, ni la izquierda ni la derecha. De una parte, tenemos a una izquierda víctima de la nostalgia de tiempos pasados en los que países como Cuba, Chile o Nicaragua pusieron en marcha auténticas revoluciones sociales que fueron derrotadas o fracasadas. Luego vinieron otras experiencias, como Venezuela, Ecuador o Bolivia, que han resultado también fallidas.

Para amplios sectores de la izquierda hispana es como si no hubiera pasado el tiempo. En buena medida se esfumaron la ilusión y los sueños de haber encontrado la puerta a un mundo mejor, sin injusticias y con plenos derechos para todos. No obstante, en gran parte de la izquierda española - preocupantemente desinformada- no se observa una evolución crítica del pensamiento, sino más bien grandilocuencia y justificaciones de actos y políticas tan poco democráticas como inefectivas o, incluso, perjudiciales para los sectores más vulnerables. Aquellos programas políticos de transformación social que en el pasado fueron encabezados por carismáticos líderes populares siguen siendo vistos con una indulgencia sorprendente. Pareciera que el fin justifica los medios, aunque el fin 
prometido -el de la desaparición de la extrema injusticia social y del racismo clasista- ni siquiera sea ya imaginable. El caso de Cuba y su revolución es, sin lugar a duda, el más evidente.

En nuestra opinión, la nostalgia derivada de aquel sentimiento de orfandad revolucionaria que describía la escritora chilena Marcela Serrano, junto al profundo desconocimiento de la realidad social y política actual del continente americano, provoca esa falta de pensamiento crítico $\mathrm{y}$, en consecuencia, una aguda ceguera. Ambas cosas no hacen sino dejar en evidencia a aquellos que, por parte de las izquierdas: a) aceptan como referente progresista lo que son más bien sistemas fallidos y, en ocasiones, hasta claramente autoritarios, cuando no dictatoriales; b) cierran los ojos frente a realidades como la venezolana, ante la que se echa en falta una clara desaprobación tanto de la represión que se vive en las calles, como de la evidente incapacidad del gobierno de Nicolás Maduro para mantener a flote la economía del país.

De otra parte, tenemos a una derecha que busca constantemente la confrontación y está siempre dispuesta a desacreditar a sus adversarios. En otras palabras, la derecha española ha convertido en práctica habitual y sostenida tratar de transformar los asuntos latinoamericanos que le interesan en temas de política interior, y siempre con la clara intención de erosionar a una izquierda que en ocasiones da demasiadas facilidades para ello.

Las derechas hispanas intentan demonizar las políticas de transformación social que abanderan los gobiernos populistas, emparentándolas con un comunismo de caricatura y esgrimiéndolas como arma arrojadiza con la intención de perjudicar la imagen de sus adversarios en España. La derecha tradicional, con la contribución de Vox, no sólo hizo ostentación de su apoyo al venezolano Juan Guaidó, sino que, además, sigue acusando a Pedro Sánchez de ser, en buena medida, el causante de todo lo terrible que sucede en dicho país. Un planteamiento tan absurdo como irreal que confunde el ejercicio de la oposición con el acoso y derribo inmisericorde al gobierno de coalición entre el PSOE y Unidas Podemos.

A juzgar por los usos políticos con fines exclusivamente electoralistas, tal parece que a la derecha hispana no le importan lo más mínimo los avances en materia social experimentados en países como Bolivia, por ejemplo. Avances que son indiscutibles, más allá de lo censurable que haya habido en el desempeño de Evo Morales. Ellos sólo parecen atender a las sombras, que evidentemente también existen y no son menores, como hemos visto.

Las derechas españolas imitan a la derecha estadounidense cuando utiliza, por ejemplo, sus relaciones con Cuba como asunto de política interna. En los tiempos en los que vivimos, la isla caribeña es para los Estados Unidos un problema fundamentalmente doméstico, por cuanto incide de manera decisiva en una realidad electoral candente como es siempre la del estado de La Florida. 
De esa forma y manera, las derechas partidarias españolas se esfuerzan por convertir asuntos latinoamericanos en problemas de política interior.

En el fondo, hay que decirlo, y en ello coinciden conservadores y progresistas, América Latina es profundamente desconocida e ignorada, más allá de los discursos vacíos, especialmente de los emitidos desde el nacionalismo españolista. Paralelamente, continúan vigentes buena parte de los clichés incorporados por unos y por otros desde los años de la segunda mitad del siglo pasado, cuando el mundo era bipolar y la realidad tendía a verse en blanco y negro. 


\section{Referencias bibliográficas:}

Alcàzar, J. “Indigenisme, democràcia i pacte social” en L'Espill, Segona Època, (2006) Número 23, pp. 34-43.

Alcàzar, J. "La imposible cubanización de Venezuela" en Mirada Hispánica, University of Virginia, $\mathrm{n}^{\mathrm{0}}$ 15, 2017, pp. 29-54.

Alcàzar, J.: "Petróleo, Venezuela, Cuba. Negros nubarrones cubren el horizonte del lumi-noso Caribe", en El Cronista Periférico, https:// elcronistaperiferico.blogspot.com/2015/03/petroleo-venezuela-cuba-negros. html

Clavero, B.: "Bolivia, de plurinacional a cívica" (2019), Conversación sobre la Historia https://conversacionsobrehistoria.info/2019/11/17/boliviade-plurinacional-a-civi-ca/?fbclid=IwAR3pEcJSZqdLDikHW4LVGIWTTON kBWcrBOgQzeXSh8gA6Fq2VTlX4jp_iEw

Ortiz, R.: "Venezuela: la tormenta perfecta", PDUH-UNAM, 2014. http:// www.pudh.unam.mx/perseo/venezuela-la-tormenta-perfecta/

Roca Barea, E. Imperiofobia y leyenda negra: Roma, Rusia, Estados Unidos y el Imperio español, Madrid, Siruela, 2016.

Stefanoni, P.: "La izquierda latinoamericana frente a Venezuela", Nueva Sociedad, febrero 2020, vid. https://nuso.org/articulo/izquierda-VenezuelaChavez-Maduro/

Straka, T.: "Urgente, Venezuela", Revista Nueva Sociedad, enero 2019,

https://nuso.org/articulo/urgente-venezuela/?utm_source=email\&utm medium=email 